\title{
A EXPERIÊNCIA COM OS COMPLEXOS DE ESTUDO NAS ESCOLAS PAULO FREIRE E SEMENTE DA CONQUISTA
}

\author{
LA EXPERIENCIA CON COMPLEJOS DE ESTUDIO EN LAS ESCUELAS PAULO \\ FREIRE Y SEMENTE DA CONQUISTA
}

\section{THE EXPERIENCE WITH THE STUDY COMPLEXES AT THE PAULO FREIRE AND SEMENTE DA CONQUISTA SCHOOLS}

\author{
Edilaine Aparecida Vieira ${ }^{1}$ \\ https://orcid.org/0000-0002-6634-0118 \\ Sandra Dalmagro ${ }^{2}$ \\ https://orcid.org/0000-0001-9639-7070
}

\begin{abstract}
Resumo: Discute a experiência das Escolas de Ensino Médio Paulo Freire e Semente da Conquista, localizadas em Abelardo Luz, oeste catarinense. É resultado de um projeto que articula pesquisa e extensão, o qual envolve a Universidade Pública e as Escolas em questão e se desenvolve há seis anos, tendo por foco a formação de professores e a organização do trabalho pedagógico com base nos complexos de estudo. Os complexos são uma formulação da Pedagogia Socialista Soviética no período inicial da Revolução Russa, e tem sido atualizado em escolas ligadas ao Movimento Sem Terra - MST. Trata-se de uma pesquisa bibliográfica nos chamados pioneiros da pedagogia soviética, favorecida por novas traduções e publicações na última década. Realizaram-se ainda observações em todo o processo, registradas em cadernos próprios e tomamos por base relatórios, avaliações e depoimentos
\end{abstract}

\footnotetext{
${ }^{1}$ Doutora e Mestre em Educação pela Universidade Federal do Paraná. Integra o Núcleo de Pesquisa em Publicações Didáticas NPP/UFPR. Email: edilaaparecidavieira@gmail.com

${ }^{2}$ Pós-doutora pelo Instituto de Educação da Universidade de Lisboa, Doutora em em Educação pela UFSC. Professora no Departamento de Estudos Especializados em Educação e do Programa de Pós-Graduação em Educação da Universidade Federal de Santa Catarina. Integra o Núcleo de Estudos sobre as Transformação no Mundo do Trabalho -TMT/UFSC.Email: sandradalmagro@yahoo.com.br
}

Como referenciar este artigo:

DALMAGRO, Sandra Luciana; VIEIRA, Edilaine Aparecida. A experiência com os Complexos de Estudo nas escolas Paulo Freire e Semente da Conquista.

Revista Pedagógica, v. 23, p. 1-21, ano 2021. DOI http://dx.doi.org/10.22196/rp.v22i0.6381 
de professores e estudantes. Nosso objetivo é o de registrar e refletir a experiência, identificando possibilidades e limites do trabalho pedagógico que se propõe superador das pedagogias burguesas.

Palavras-chave: Pedagogia Socialista. Complexos de estudo. Educação no MST.

Resumen Analiza la experiencia de las escuelas secundarias Paulo Freire y Semente da Conquista, ubicadas en Abelardo Luz, al oeste de Santa Catarina. Es el resultado de un proyecto articulado de investigación y extensión, que involucra a la Universidad Pública y las Escuelas en cuestión y se desarrolla desde hace seis años, con foco en la formación docente y la organización del trabajo pedagógico a partir de los complejos de estudio. Los complejos son una formulación de la Pedagogía Socialista Soviética en el período inicial de la Revolución Rusa, y se han actualizado en las escuelas vinculadas al Movimiento de los Sin Tierra - MST. Se trata de una búsqueda bibliográfica de los llamados pioneros de la pedagogía soviética, favorecida por las nuevas traducciones y publicaciones de la última década. También se realizaron observaciones a lo largo del proceso, registradas en cuadernos específicos y en base a informes, evaluaciones y testimonios de docentes y alumnos. Nuestro objetivo es registrar y reflejar la experiencia, identificando posibilidades y límites del trabajo pedagógico que se propone superar las pedagogías burguesas.

Palabras clave: Pedagogía socialista. Complejos de estudio. Educación en el MST.

Abstract Discusses the experience of the Paulo Freire and Semente da Conquista High Schools, located in Abelardo Luz, west of Santa Catarina. It is the result of an articulated research and extension project, which involves the Public University and the Schools in question and has been developed for six years, focusing on teacher training and the organization of pedagogical work based on the study complexes. The complexes are a formulation of Soviet Socialist Pedagogy in the early period of the Russian Revolution, and have been updated in schools linked to the Landless Movement - MST. This is a bibliographic search of the so-called pioneers of Soviet pedagogy, favored by new translations and publications in the last decade. Observations were also made throughout the process, recorded in specific notebooks and based on reports, evaluations and testimonies from teachers and students. Our objective is to register and reflect the experience, identifying possibilities and limits of the pedagogical work that proposes to overcome bourgeois pedagogies.

Keywords: Socialist Pedagogy. Study complexes. Education in the MST. 


\section{INTRODUÇÃO}

O artigo apresenta de forma reflexiva a experiência das Escolas de Ensino Médio Paulo Freire e Semente da Conquista, localizadas em assentamentos de Reforma Agrária do MST em Abelardo Luz, oeste catarinense. Revela um processo formativo desenvolvido na parceria entre a escola pública, a universidade e o movimento social, articulados em torno da discussão sobre a formação professores e organização do trabalho pedagógico, explorando elementos que se encontram na perspectiva da Pedagogia Socialista Soviética e dos Complexos de Estudo. Os complexos são uma formulação da Pedagogia Socialista no período inicial da Revolução Russa (1917-1931), a qual tem ganhado espaço junto a escolas ligadas ao Movimento Sem Terra - MST.

Além de professores e direção, neste processo os estudantes também estiveram envolvidos de diversas formas, os quais se encontram organizados em Núcleos de Base e por turmas; contribuíram ainda as organizações coletivas dos assentados e as famílias dos estudantes. A formação e o planejamento foram realizados mediante estudos, debates e pesquisas na realidade, com destaque para os inventários, estes se debruçaram sob os diversos aspectos das escolas, dos assentamentos, do município e da região. Este processo se revela na elaboração de planejamentos coletivos do trabalho pedagógico por complexos, considerando as disciplinas, as áreas do conhecimento, e algumas linhas gerais para a auto-organização dos estudantes e o Trabalho Socialmente Necessário.

O presente artigo utiliza de pesquisa bibliográfica dos chamados pioneiros da pedagogia soviética, favorecida por novas traduções e publicações na última década. Realizamos ainda observações em todo o processo, registradas em cadernos próprios e tomamos por base relatórios, avaliações e depoimentos de professores e estudantes.

Nosso objetivo é o de registrar e refletir a experiência, identificando possibilidades e limites do trabalho pedagógico que se propõe superador das pedagogias burguesas. No texto que segue, caracterizamos as escolas e a proposta soviética dos complexos e, na sequência, oferecemos um panorama do trabalho realizado, concluindo com reflexões 
críticas sobre o mesmo.

\section{CONTEXTO HISTÓRICO DAS ESCOLAS E A ORGANIZAÇÃO DO TRABALHO PEDAGÓGICO POR COMPLEXOS DE ESTUDO}

A criação das Escolas Paulo Freire e Semente da Conquista, no ano de 2004, representam a materialidade da luta no campo da educação, enfrentada pelos assentados do município de Abelardo Luz-SC. O município foi berço das primeiras ocupações de terra, organizadas pelo MST, no estado de Santa Catarina, num processo de luta constante na década de 1990, cercada de violência, despejos, repressão, mas também esperança e trabalho coletivo. Hoje são cerca de 1500 famílias, em 22 assentamentos, que tornam o município referência na luta por reforma agrária.

Devido ao número de famílias assentadas e à extensão territorial, duas regiões se tornaram referência: os assentamentos 25 de Maio e José Maria, com estruturas de posto de saúde, escolas de Ensino Fundamental, cooperativa, igrejas, salão comunitário, rádio, entre outras. Ali também foram edificadas as escolas de Ensino Médio. As escolas buscam pautar seu trabalho nas perspectivas emancipatórias, com destaque para a Pedagogia do MST (MST, 2005).

A luta pela valiação nte da escola acompanha a luta pela transformação social. De acordo com Bicalho (2021, p.13) "a luta pela terra é um projeto de transformação não somente econômica. Ela compreende a possibilidade dos sujeitos, individual e coletivo, atuarem no processo de transformação da realidade". É neste sentido que o MST tem valiação ao longo das últimas quatro décadas uma educação pautada nas perspectivas críticas, em particular na educação popular com base valiação nte nas produções de Paulo Freire e na Pedagogia Socialista (Russia 1917-1931) as quais se revelam na Pedagogia do Movimento.

A leitura dos clássicos russos, realizada de forma tímida (pelos poucos textos traduzidos) nas discussões iniciais do Setor de Educação do MST, na década de 1980, e de forma mais expressiva na última década, em particular a partir do acesso aos clássicos daquele período, tem contribuído de forma significativa para a construção de experiências 
como esta, registrada neste artigo. As novas traduções, o estudo coletivo e experiências em escolas na última década, permitiram avanços do ponto de vista teórico e prático nas escolas e nas formulações pedagógicas do Setor de Educação do MST.

Nas escolas Paulo Freire e Semente da Conquista as primeiras discussões chegam com os professores que, paralelo ao trabalho nas escolas, participavam da formação inicial no curso de Licenciatura em Educação do Campo realizado em Veranópolis, em uma parceria entre a UnB, Iterra - Instituto de Educação Josué de Castro - por meio do PRONERA - Programa Nacional de Educação na Reforma Agrária. A discussão também estava no Setor de Educação do MST e logo reflete nas escolhas das próprias escolas, pois havia um cenário favorável, frente à história das escolas e de experiências anteriores com o trabalho com temas geradores, eixos temáticos e ainda motivados pelo fato da escola Paulo Freire oferecer, desde 2009, um curso médio integrado na área técnica em Agroecologia e pautar desafios na articulação entre teoria e prática, a relação entre o conteúdo e a realidade, entre outros.

A proposta dos complexos estava em sintonia com o Projeto Político Pedagógico da escola e com o trabalho que de fato vinha sendo desenvolvido. Por outro lado, parecia poder contribuir para superar as limitações que vinham sendo identificadas. Neste processo, a busca de formação continuada logo foi pautada, pois a estrutura da escola, o tempo e espaço disponível para formação era e continua sendo um problema, atreladas à necessidade de orientação teórica e prática para o desenvolvimento da proposta. Neste sentido, a parceria entre a escola a Universidade Federal de Santa Catarina, o Instituto Federal Catarinense e o Setor de Educação do MST foi firmada e possibilitou um avanço significativo na construção da organização do trabalho pedagógico a partir dos complexos. Processo que iniciou em 2012 e segue até os dias atuais.

Inicialmente o grupo de professores fez a opção por constituir um grupo de estudo, que se centrou na leitura e discussão dos clássicos da experiência Russa, entre eles o livro Fundamentos da Escola do Trabalho (PISTRAK, 2000), o que envolveu praticamente todos os professores. As discussões que cercavam o debate sobre a Pedagogia Socialista se aproximavam daquilo que a escola defendia enquanto Projeto Político Pedagógico, por exemplo, o anseio de que o conhecimento precisa ter sentido concreto, útil, não meramente escolástico, mercantil, mas social, científico, humanista e integral, 
considerando o sujeito em suas amplas dimensões: ética, social, cientifica, artística, corporal, entre outras.

A Pedagogia Socialista Russa é uma vertente de suporte às formulações educacionais do MST desde o início da década de 1980. Quanto aos complexos de estudo, inicialmente é preciso considerar que esta proposta foi gestada no período entre 1917 e 1931, no contexto da Revolução Russa, a qual, no campo educacional, propunha-se a criar uma nova escola. As diferenças históricas, políticas e geográficas que se colocavam entre a realidade russa e brasileira não foram desconsideradas, não se tratou de copiar aquela experiência, mas de tomá-la como base de estudos e criação, a partir de nossas próprias condições e desafios.

A organização pedagógica tendo como referência os complexos de estudo tem sido um grande desafio para as escolas, as quais precisam constantemente se reorganizar, pois, a estrutura da escola pública na sua forma atual é fechada, o que limita o desenvolvimento de muitas atividades pedagógicas. Os complexos de estudo constituem uma proposta educativa que articulam em si, ao mesmo tempo, trabalho, conhecimento das bases das ciências e das artes (na forma de conteúdos e objetivos de ensino), a auto-organização dos estudantes, métodos específicos de ensino das disciplinas envolvidas no complexo e práticas de valiação do conjunto das dimensões trabalhadas em cada período de estudos (SAPELLI; FREITAS; CALDART, 2015, p. 14).

\subsection{Complexos de estudo: breve caracterização}

Como assinalado, o trabalho das Escolas Paulo Freire e Semente da Conquista com os complexos de estudos formulados pela Pedagogia Socialista Russa se insere em um contexto mais amplo, no qual o trabalho nestas escolas é uma parte. Neste sentido, não cabe neste artigo explorar a profundidade desta formulação pedagógica, apenas trazer alguns aspectos centrais com vistas a melhor situar o leitor no debate que buscamos. $\mathrm{O}$ aprofundamento deste estudo pode ser encontrado em Pistrak (2009, 2015 e 2018), Shulgin (2013), Krupskaya (2017), MST/PR (2013), dentre outros. Na presente síntese, nos valemos de outros escritos em que debatemos a questão (DALMAGRO, MOURA, 2012; DALMAGRO, 
2016).

Inicialmente é preciso considerar que a proposta dos Complexos de Estudo foi gestada na URSS no período entre 1917 e 1931, no contexto da Revolução Russa, a qual, no campo educacional, propunha-se a criar uma nova escola, uma escola que contribuísse para a edificação do socialismo. Ao nos inspirarmos em uma proposta que se desenvolve relativamente distante de nós, no tempo e no espaço, não desconsideramos algumas diferenças enormes que se colocavam entre estas duas realidades (russa e brasileira), mas procuramos referências que nos possibilitassem ampliar ou modificar a perspectiva posta de educação escolar. Ideais basilares da experiência soviética como formar os "construtores do futuro", ou seja, a autoconsciência e a autodireção dos estudantes e trabalhadores na edificação da história, a relação teoria e prática e a formação ampla/omnilateral são questões centrais também no projeto das escolas Paulo Freire e Semente da Conquista.

Os complexos, formulação da didática socialista, visam operacionalizar a escola do trabalho. Na experiência russa, eles são entendidos como "a complexidade concreta dos fenômenos, tomados da realidade e unificados ao redor de um determinado tema ou idéia central” (NARKOMPROS, 1924, apud FREITAS, 2009, p. 36). A definição do complexo de estudo não ocorre apenas pela aproximação à realidade do educando, mas pela centralidade social que a questão comporta. Na perspectiva materialista histórica dialética, a realidade é complexa, constituindo-se como totalidade. Local e geral se encontram em relações recíprocas e interdependentes. Para Freitas (2009, p. 36), “a complexidade concreta dos fenômenos remete à vida, e esta à questão do trabalho". Os Complexos são então, para esse autor, uma tentativa de superação da escola verbalista clássica, buscando a unidade entre teoria e prática. Nesse sentido, o Complexo não é apenas um "tema”, mas a articulação entre a atualidade, a auto-organização e o trabalho. A articulação profunda dessas dimensões no método da escola está evidenciada na seguinte passagem de Pistrak:

O objetivo que os alunos devem atingir é não somente estudar a realidade atual, mas também se deixar impregnar por ela. A consequência é que os antigos métodos de ensino não podem mais servir, é preciso estudar os fenômenos em suas relações, sua ação e dinâmicas recíprocas, é preciso demonstrar que os fenômenos que estão acontecendo na realidade atual são simplesmente partes de um processo inerente ao desenvolvimento histórico geral, é preciso demonstrar a essência dialética de tudo que existe, mas uma demonstração desse 


\section{Revista do Programa de Pós-Graduação em Educação da Unochapecó ISSN 1984-1566 (on-line) ISSN 1415-8175 (impressa)}

tipo só é possível na medida em que o ensino se concentre em torno de fenômenos constituídos em objetos de estudo: assim, a questão do ensino unificado, da concentração do ensino por complexos, torna-se, uma questão candente; a questão do método que agora se coloca não é simplesmente a questão de uma assimilação melhor e mais completa destes ou daqueles estudos; trata-se de uma questão que se relaciona com a essência do problema pedagógico, com o conhecimento dos fenômenos atuais em suas relações e dinâmicas recíprocas, isto é, com a concepção marxista da pedagogia (PISTRAK, 2000, p. 35).

Neste entendimento é que se pretende aproximar a escola da vida, superando a escola tradicional, de conteúdos abstraídos do real, cujo ensino não dialoga com o estudante. Enfatiza-se que a escola é lugar de vida e não apenas de preparação para ela. A nova forma deve favorecer a vida de modo integral, o estudante como sujeito ativo, o conhecimento vivo da realidade e a capacidade de ação sobre ela. A socialização do conhecimento e da cultura é essencial para viver e atuar no mundo, para formar os “construtores do futuro”, mas não se dá separadamente do real, mas pela atuação neste, pelo estudo de situações concretas. Na proposição dos complexos, a aprendizagem que se desenvolve a partir de situações reais requer ligação entre as disciplinas ou conteúdos com a vida de um modo não artificial, mas pelo estudo e resolução das situações concretas, o que coloca o trabalho e a auto-organização como elementos fundamentais.

Para alcançar este propósito, a escola não pode ser sinônimo de sala de aula, onde se ensina apenas através da verbalização, apenas falando sobre a vida, mas deve se organizar acolhendo na dinâmica escolar o trabalho produtivo ou socialmente necessário e a organização coletiva ou auto-organização dos estudantes. Nesta perspectiva, são necessárias as saídas de campo, as viagens de estudos, os laboratórios, os grupos de estudo, o estudo individual, entre outros, incluindo as aulas (gabinetes de estudo) que favoreçam a apreensão e a intervenção na realidade de modo cada vez mais claro, profundo e articulado.

Um complexo representa uma "complexidade" cujo entendimento a ser desvendado pelo estudante ativa sua curiosidade e faz uso dos conceitos, categorias e procedimentos das várias ciências e artes que são objeto de ensino em uma determinada série. O complexo tem uma prática social real embutida em sua definição. Ele é mais que um tema ou eixo e não se resume à idealização de uma prática que apenas anuncia a aplicabilidade longínqua de uma aprendizagem. É o palco de uma exercitação teórico-prática que exige do estudante as bases conceituais para seu entendimento, permite criar situações para exercitação 
prática destas bases plenas de significação e desafios e ao mesmo tempo permite que estes conceitos sejam construídos na interface da contribuição das várias disciplinas responsáveis pela condução do complexo. O complexo é uma unidade curricular do plano de estudos, multifacetada, que eleva a compreensão do estudante a partir de sua exercitação em uma porção da realidade plena de significações para ele. Por isso, o complexo é indicado a partir de uma pesquisa anteriormente feita na própria realidade das escolas (...). É uma exercitação teórico-prática que acontece na realidade existente no mundo do estudante, vivenciada regularmente por ele em sua materialidade cotidiana e que agora precisa ter sua compreensão teórica elevada (MST/PR, 2013, p.22).

Para se ligar à vida três categorias destacam-se nas formulações de Pistrak: o trabalho, a auto-organização e a atualidade. O trabalho é a base da vida e da educação adentra na escola não como atividade pontual ou ilustrativa, mas como trabalho real, socialmente útil, o qual comporta em si contradições, organização coletiva e é base do conhecimento (LUKACS, 1984). A auto-organização busca exercitar a autodisciplina e organização para as atividades individuais e coletivas, passando pelo seu exercício intencional na escola em vista de promover a participação da população no conjunto da construção do país. Liga-se, portanto, a uma perspectiva de socialismo, experimentado nos soviets, cujos rumos da sociedade socialista encontravam-se nas mãos do povo, dos trabalhadores e não apenas dos dirigentes partidários.

Os complexos também são definidos tomando por base a atualidade, portanto, com capacidade de conter determinações políticas, científicas e culturais fundamentais, daí que por meio do complexo o estudante é levado a se situar na totalidade e complexidade social de maneira profunda e embasada no materialismo histórico dialético. Destaca-se também a articulação da escola com o meio ou com o conjunto de agências educativas existentes no entorno dela, as quais possuem potencialidade formativa nas quais a escola poderá se apoiar. Em síntese, trata-se de uma proposta pedagógica experimentada por uma sociedade nova em construção que precisa reconstruir também a escola como espaço privilegiado de formação das novas gerações. Estes desafios nos parecem bastante atuais.

A unidade complexo reúne, sempre, em uma mesma propositura, o trabalho material como método geral (ora como ligação com o trabalho produtivo, ora como prática social mais ampla - mas sempre como trabalho socialmente útil), as bases das ciências e das artes (classicamente denominadas de conteúdos de ensino, ou o conhecimento historicamente acumulado pela humanidade passível de ser abordado naquela série e idade da criança, na forma de conteúdos e objetivos de ensino), os processos de desenvolvimento da auto-organização 
inseridos em seus objetivos formativos, bem como os métodos específicos de domínio das disciplinas envolvidas no complexo, as quais fazem uso de inúmeras fontes educativas do meio onde vive o estudante (MST PR, 2013, p. 22).

O sistema de complexos é, portanto, uma forma de organização do trabalho escolar que articula as experiências educativas dos estudantes, o trabalho, a auto-organização e o conhecimento, elaborado em vista da compreensão da complexidade do real, da interligação dos fenômenos por meio do estudo sistemático e da inserção efetiva dos estudantes no meio. Nesse sentido, o complexo é um “edifício sistemático”, construído a partir do acúmulo de observações e estudos, a partir do qual "procede-se uma síntese", compondo um quadro completo de determinado tema (NARKOMPROS, 1935, p. 107).

\section{OS COMPLEXOS DE ESTUDO NAS ESCOLAS PAULO FREIRE E SEMENTE DA CONQUISTA}

Como já salientado, a opção de orientar a organização do trabalho pedagógico das escolas Paulo Freire e Semente da Conquista na direção dos Complexos de Estudo é uma decisão que se ancora no trabalho anterior da escola, ao mesmo tempo em que organiza, dentro de condições dadas, seu processo para tal. Nesse sentido, contavam: o grupo de estudos e a formação permanente dos educadores, as formas iniciais de auto-organização dos estudantes e o trabalho socialmente útil desenvolvido nas escolas. Quanto à autoorganização dos estudantes, esta se expressa nos Núcleos de Base (como rádio, bem estar, higiene e limpeza, esportes, infraestrutura...) os quais se voltam à realização de atividades necessárias e/ou de interesse dos estudantes, sendo ao mesmo tempo espaço importante para construção de autonomia e auto-organização. Um desafio tem sido o de aproximar os Núcleos de Base dos estudos e dos complexos, sem que percam sua característica de realizar o trabalho socialmente útil e a auto-organização. Além dos Núcleos os estudantes também possuem uma organização nas turmas e realizam assembleia geral da escola uma vez por semestre ou quando necessário, participando ativamente do processo de fluxo de informação e decisão das questões da escola, seguindo a lógica da gestão democrática.

Considerando que os complexos têm como pressuposto a articulação com o meio, as organizações dos assentamentos, principalmente os Setores de Educação e Produção 
do MST, a Cooperativa, a Equipe Técnica, parte dos assentados, em particular os familiares dos estudantes, contaram na decisão de experimentar esta proposta pedagógica. Quanto à equipe de docentes, percebia-se um coletivo comprometido com a escola e disposto a pensar um processo diferente, que permitisse avançar em relação aos aspectos que já estavam sendo desenvolvidos. Essas bases de apoio têm sido essenciais para o desenvolvimento desta experiência, porém também apresentam fragilidades que limitam o aprofundamento da proposta.

Nas escolas Paulo Freire e Semente da Conquista o processo de formação dos professores e o planejamento ocorre de modo articulado. A sistemática básica consistia em localizar o trabalho antes realizado e os objetivos para o próximo período; estudo de questões a partir dos apontamentos do grupo; orientações e planejamento geral da escola, das áreas, das disciplinas, da auto-organização e do trabalho socialmente necessário. Os encontros ocorreram no período entre 2014 e 2019, com encontros geralmente no início do ano escolar e mais um ou dois encontros no decorrer de cada ano. O coletivo dos educadores da escola, quando dos planejamentos anuais, já havia construído uma avaliação do trabalho anterior e realizado elaborações acerca da porção da realidade/complexo a ser trabalhado no período seguinte. O trabalho de assessoramento consistia em fazer aparecerem às explicações e os motivos das sugestões postas. O grupo analisava a atualidade da proposta, os vínculos com os conteúdos previstos e a coerência com os objetivos de formação. Com frequência um conjunto de disciplinas (professores) se sentia melhor acolhidas em face do complexo proposto, enquanto um grupo mais reduzido percebia menores possibilidades de articulação. Quando necessário, definiu-se por trabalhar com mais de um complexo simultaneamente ou mesmo identificar áreas ou aspectos dentro de uma mesma porção do real. Neste processo, buscou-se provocar a reflexão dos professores, a interdisciplinaridade e o registro dos vínculos e do conjunto das definições.

Do ponto de vista da delimitação dos complexos ou porções da realidade, estes resultam da interrelação que se estabelece entre os inventários da realidade, os conteúdos previstos e os objetivos de formação. Na sequência, localizaremos cada um destes aspectos. A delimitação das porções não seguiu um processo rigoroso de vínculos entre os inventários e os conteúdos e nem foi possível identificar sempre as múltiplas e mais 
ISSN 1984-1566 (on-line) ISSN 1415-8175 (impressa)

relevantes articulações possíveis, para o que o exíguo tempo de planejamento foi decisivo.

O Inventário da Realidade é um processo importante na construção do plano de estudos. Nas escolas Paulo Freire e Semente da Conquista, iniciamos por inventariar as próprias escolas, no sentido de refletir sobre o caminho que já havia sido percorrido desde sua origem em 2004. Neste processo, algumas questões foram fundamentais: o que as escolas já tinham experimentado, do ponto de vista pedagógico? Quais os pontos fortes e os limites das escolas? Que escola queremos construir? Que estudantes queremos formar? Como a escola se articula com o seu entorno?

Durante as discussões se percebeu diferenças entre as escolas, em particular em relação à estrutura física. O curso técnico, do qual falaremos adiante, permitiu um avanço significativo do ponto de vista das condições materiais na Escola Paulo Freire e uma ampliação no grupo de professores. De um lado a ausência de estrutura física dificultava os trabalhos na Escola Semente da Conquista, por outro lado, a falta de formação dos professores para trabalhar com os laboratórios e seus equipamentos modernos também era um problema na Escola Paulo Freire.

Neste processo foi possível perceber sinais positivos para a discussão sobre o politecnismo, em especial pela presença de um curso técnico na escola Paulo Freire, e com isso a disposição de animais, terra, laboratórios; a possibilidade de planejar, gerenciar e a necessidade de dar funcionamento ao curso e à própria escola, inclusive no que diz respeito à alimentação. A escola era um laboratório vivo, semelhante aos lotes rurais das famílias assentadas. Neste mesmo sentido, o trabalho que se realizava nas escolas com teatro, jornal, rádio, produção agrícola, articulado à auto-organização, também sinalizava questões positivas e em andamento.

O inventário da realidade contemplou condições gerais das próprias escolas, as famílias, os assentamentos, aspectos do município e do país. O objetivo foi registrar e entender quais as principais questões, características e forças que afetam cada um destes espaços. A partir dos dados coletados e relatos dos grupos que inventariaram cada uma das dimensões, foi possível ter um mapa geral das principais questões. Ressaltamos que todo o coletivo escolar foi envolvido na realização dos inventários, coordenação, professores e estudantes. Aos estudantes, coube fundamentalmente inventariar a realidade de suas famílias e assentamentos, através de processos de pesquisa e 
sistematização articulados a algumas das disciplinas escolares.

Cada professor também inventariou sua própria disciplina, na ideia de analisar seus conteúdos, assim como a distribuição dos conteúdos em cada ano. Foi orientado a registrar o processo de definição dos conteúdos e metodologias, o que consideraram quando de tais opções, de onde vem os conteúdos que estão trabalhando, que materiais utilizam para elaboram dos planos de estudo, etc.

Os dados e as discussões possibilitaram interrogar os professores acerca de suas escolhas - ou das escolhas que outros fizeram antes deles - sendo que um dos objetivos deste processo é desnaturalizar os conteúdos selecionados e sua ordem, visando à reflexão do docente e sua maior apropriação acerca do trabalho pedagógico que desenvolvem quanto aos conhecimentos elaborados pela humanidade.

Este processo também levou o grupo de docentes a traçar os objetivos formativos, os quais tem um sentido amplo, de formação humana. Eles não são restritos a uma disciplina e não costumam estar explícitos nas escolas. Pensar sobre eles, registrá-los, é uma forma de deixar explícita a intencionalidade formativa. Seguem alguns deles:

\footnotetext{
Perceber a vinculação entre escola e vida, especialmente a partir de diferentes matrizes formadora, tais como: trabalho, luta social, organização coletiva, cultura e história;

Compreender a relação entre educação e trabalho, pois o trabalho constitui a base principal do projeto educativo e da vida;

Desenvolver a capacidade coletiva de análise da situação atual da sociedade, mundo, do país, do local onde os sujeitos moram, sempre relacionando com o contexto geral e o movimento da história;

Compreender a dimensão educativa da luta social e da organização coletiva, analisando o movimento da história e percebendo que a luta social pode ser objeto de estudo cientifico na escola. Também compreendendo que a luta é um processo permanente;

Estimular e criar possibilidades de participação dos estudantes e da comunidade no cotidiano da escola, desenvolvendo trabalho socialmente necessário na escola e na comunidade, construindo processos de auto-organização e gestão coletiva; Construir processos de valorização da experiência humana, do jeito de ser humano, dos modos de vidas, da cultura. Criticar a cultura hegemônica, a indústria cultural e estimulando o cultivo da memória coletiva, a formação de uma consciência histórica, valorizando a Arte, a Educação Física (ESCOLAS PAULO FREIRE E SEMENTE DA CONQUISTA, 2015).
}

Outra questão importante que acompanha a proposta dos complexos de estudo é o Trabalho Socialmente Necessário - TSN (SHULGIN, 2013). O TSN é aquele que assume seu caráter útil para o coletivo. Ele pode e deve extrapolar a escola, pode ter um valor 
econômico, mas fundamentalmente um valor pedagógico. Na experiência desenvolvida na escola este tem sido um desafio: construir processos que saiam da escola e cheguem até as famílias, mas assinalamos como exemplos de TSN o resgate da história e construção da memória dos assentamentos, realizado pelas escolas todos os anos em comemoração ao aniversário do MST em Santa Catariana e no Município de Abelardo Luz. Esta atividade envolveu as famílias, o resgate de elementos da cultura local (alimentação, brincadeiras, música, imagens), a contação de causos, palestras, entre outros. Ao longo do tempo surgiu a proposta de construção de um museu na escola, para guardar os vários objetos, imagens, documentos que todos os anos são trazidos pelos alunos e famílias. Hoje, na escola Paulo Freire já é possível perceber a materialização desta ideia. O museu, ainda em construção, conta com um pequeno acervo de fotografias e vídeos históricos e elementos artísticos construídos pelos alunos, como por exemplo, um conjunto de quadros com Semente produzidos no ano de 2019, uma maquete do Casarão, símbolo histórico da luta pela terra da região, dentre outros objetos.

\subsection{O trabalho com as porções da realidade: socializando o processo}

A definição dos complexos ou porções da realidade que oferecem unidade ao trabalho escolar em dado período de tempo, emerge de diversas questões sendo elas: a realidade ou atualidade (captada ao menos em parte nos citados inventários), os conteúdos das disciplinas ou seus objetivos de instrução e os objetivos de formação das escolas. Em 2015, primeiro ano a realizar um trabalho mais diretamente orientado pelos complexos de estudo, a opção foi pela porção Agroindústria. O processo foi planejado, como forma de experiência para ser desenvolvido com o $2^{\circ}$ ano do Ensino Médio, o que de fato ocorreu, mas acabou por envolver as demais turmas ainda que de forma não tão planejada e sistemática. Entre as motivações para esta escolha da porção Agroindústria está o fato de Abelardo Luz ser considerada a capital da semente de soja e reunir diferentes forças representativas do modelo de agricultura do agronegócio, ligado a empresas multinacionais no comércio de grãos e de carnes que buscam nas áreas de Reforma Agrária força de trabalho barata. O fato de os assentamentos estarem rodeados por fazendas, na 


\section{Revista do Programa de Pós-Graduação em Educação da Unochapecó ISSN 1984-1566 (on-line) ISSN 1415-8175 (impressa)}

sua maioria alinhadas ao monocultivo de soja e milho, contrastava com a existência de uma cooperativa de assentados, uma filial da COOPEROESTE - Terra Viva. Esta cooperativa possui nos assentamentos de Abelardo Luz um posto de resfriamento de leite, além de outras iniciativas voltadas a articular a produção, industrialização e comercialização. Estas foram algumas das questões que se refletiram nos inventários e ajudaram na construção da porção da realidade trabalhada em 2015.

Durante este ano de 2015, avaliações bimestrais foram realizadas pelos professores e coordenação diretamente com os alunos, pensando na construção do conhecimento escolar destes jovens do ensino médio. Questionários, conversas e observações serviram de parâmetro para avançar no processo pedagógico dentro da sala de aula e na escola como um todo. Estas avaliações revelaram que em algumas disciplinas os estudantes conseguiram fazer maior relação com a porção da realidade do que em outras, e isso permitiu dar mais sentido para determinado conteúdo, segundo os alunos. Também ficou evidente que eles perceberam aproximações entre conteúdos de diferentes disciplinas. Como relata um estudante: "saber que a agroindústria tem tudo a ver com química e biologia é muito interessante, pois é tudo interligado, lá na agroindústria as coisas não são feitas separadas" (Dani, 2015, $2^{\circ}$ ano do Ensino Médio).

Esta primeira experiência forneceu elementos para que no ano seguinte, 2016, as ações fossem ampliadas. As questões que apareceram durante o trabalho com a porção agroindústria, as avaliações dos alunos, os resultados do trabalho pedagógico, o diálogo com a realidade e o inventário, delinearam novas porções, que foram denominadas Alimentação saudável e Cultura. Tais escolhas envolviam o modelo de produção agropecuária, o uso de venenos nos alimentos, o consumo de industrializados e alimentos transgênicos, as doenças, etc. No que se refere à porção Cultura destacavam-se questões como: Quem é camponês? Qual sua identidade, sua cultura? Os jovens se identificam como Sem Terra? Como a cultura burguesa adentra nos assentamentos?

Delimitadas as porções, em um primeiro momento do planejamento os professores trabalharam de forma individual, cada um buscou responder como sua disciplina poderia contribuir com a porção, e como a porção poderia contribuir com a sua disciplina, respeitando a autonomia para que cada um fizesse a opção por uma ou outra, e em alguns casos pelas duas. Em seguida, os professores se reuniram em função das aproximações 


\section{Revista do Programa de Pós-Graduação em Educação da Unochapecó ISSN 1984-1566 (on-line) ISSN 1415-8175 (impressa)}

com as porções e aspectos destas, planejando ações coletivas que foram denominadas "atividades articuladoras" como palestras, filmes, viagens de estudo, feira de saberes. Para exemplificar: as disciplinas de artes e sociologia se reuniram em torno da porção cultura quando trabalharam o resgate da história do MST em Abelardo Luz. O trabalho de pesquisa organizado pela disciplina de sociologia foi transformado em um documentário em material audiovisual, e permitiu mapear os artesãos da comunidade, poetas que foram convidados a expor na feira dos saberes, construindo um momento riquíssimo.

O ano de 2016 foi afetado pelas discussões nacionais que envolveram as mudanças do ensino médio, propagadas especialmente a partir da Medida Provisória 748/2016, lançada sem consulta à sociedade gerando diversos debate e protestos, o que causou ocupações em escolas de vários estados, inclusive nas escolas Paulo Freire e Semente da Conquista. Esta situação acabou por interromper o processo planejado pela escola, mas pautou com mais força outros elementos que compõem a proposta dos complexos de estudo, como a auto-organização. A ocupação das escolas foi assumida pelos alunos que demonstraram compromisso, capacidade de organização coletiva, boa relação entre escola e comunidade, aspectos que são princípios formativos defendidos pelas escolas e que estão presentes no processo educativo. Frases marcadas nas paredes da escola neste momento das ocupações, por exemplo: "Para que $(\mathrm{m})$ serve $(\mathrm{m})$ teu conhecimento?" demonstram o papel importante na vida destes jovens e como eles compreendem a escola e sua função social.

As demandas geradas pela ampliação da discussão e o processo de ocupação das escolas, fizeram com que o trabalho com as porções Alimentação Saudável e Cultura se estendessem para o ano seguinte, 2017. De acordo com a avaliação realizada pelos estudantes, foi possível perceber a articulação entre os conhecimentos, o diálogo entre os professores, como relata uma estudante: "trabalhamos sobre cultura nas disciplinas de geografia, história, e artes, foi muito interessante saber sobre a cultura alimentar de nossa região e a forma como eram processados os nossos alimentos" (Gracieli, aluna das escolas, 2017).

No final do ano de 2017, a partir do encerramento e avaliação das porções Alimentação Saudável e Cultura, outros elementos foram surgindo, especialmente inflamados pelas questões da conjuntura, local, mas também global. Ganhavam força 
questões envolvendo os conflitos por terra, os problemas presentes nos assentamentos da região, disputas no campo da educação e envolvendo os jovens, sua vivência, cultura, seu corpo, seus direitos, questões em conjunto que afetam a vida dos sujeitos jovens e da comunidade.

Assim, chegou-se ao consenso que o novo complexo a ser estudado seria Território, compreendendo que a partir desta discussão outras ramificações poderiam ser estabelecidas de forma a articular as disciplinas e acomodar as áreas do conhecimento. Assim, uma nova configuração foi sendo construída, organizada em três dimensões a partir da porção Território: Território, sociedade e globalização; O Assentamento: produção, trabalho e os resíduos; O corpo e a constituição do sujeito jovem. O desdobramento da porção Território em três campos foi se delineando a partir das áreas do conhecimento, ciências humanas e sociais, ciências da natureza e linguagens as quais respectivamente se dedicaram mais a um dos sub-aspectos do complexo, ainda que outras articulações também ocorressem.

Durante este processo percebemos limites, mas também observamos avanços em direção a construção da nova escola. De acordo com o depoimento de um dos alunos da escola, "que nos chama a atenção na nossa escola é a forma com que nos passam os conteúdos de forma diferenciada ligando ao nosso cotidiano" (Renam, aluno do $3^{\circ}$ ano, 2019). Reconhece-se que há um longo caminho pela frente, na construção da Escola Única do Trabalho, mas motivados por depoimentos como este é que encontramos forças para continuar. Articular teoria e prática, o conhecimento entre as disciplinas e entre as áreas, a realidade local e global, tomar o trabalho como princípio educativo e a auto-organização como forma de envolver os estudantes na escola e na comunidade são questões que seguem como possibilidades e ao mesmo tempo desafios para as escolas que procuram romper com a lógica tradicional.

\section{CONSIDERAÇÕES FINAIS}


Enguita (1989) evidencia que a escola educa pelas relações materiais que desenvolve e demonstra que a escola burguesa foi edificada para reproduzir estas relações em seu interior. O controle dos estudantes, a submissão à permanente avaliação e autoridade, a competição e impessoalidade das relações, o contato com um conhecimento desencarnado, entre outros, revelam uma escola voltada à socialização na ordem burguesa e o acesso a fragmentos do conhecimento humano. Temos afirmado que um projeto emancipado de sociedade necessita de outro projeto educacional e escolar. Nesta direção é que caminharam os pedagogos e psicólogos da Rússia Soviética e muitas escolas de assentamentos de sem terra no Brasil.

No caso das escolas em foco no presente artigo é importante ressaltar que não se trata de querer transformar radicalmente a escola, deixando intocado em seu exterior o mundo burguês. Ao contrário, são escolas localizadas em territórios de conflito social, articuladas à luta por transformações sociais profundas. A luta do MST se desdobra também na luta pela educação escolar. Trata-se, portanto, da complexidade de construir o novo em meio ao velho, sob as relações, condições e contradições que a sociedade burguesa nos legou.

Ao longo destes anos de trabalho das escolas Paulo Freire e Semente da Conquista com a proposta dos complexos de estudo, pensamos que alguns aprendizados e limitações se destacam, é com eles que encerramos este texto.

Os sucessivos encontros de estudo e trabalho coletivo foram revelando aos professores outra possibilidade de fazer escola. A escola tal qual conhecemos foi sendo desnaturalizada, isto é uma tarefa longa, importante e inconclusa. Observamos que foi assumida pelos professores a compreensão de que o conhecimento se articula ao real e somente desta forma viva é que pode ser apreendido pelos educandos; que a autoorganização dos estudantes não é uma questão menor na escola, mas parte essencial de seu trabalho pedagógico; que o trabalho coletivo é uma condição para outro projeto escolar. Os professores nos relatam maior realização profissional, mais segurança no trabalho que desenvolvem e maior interesse dos alunos.

Os estudantes ficaram mais conscientes do projeto pedagógico da escola e do trabalho articulado entre os professores, dando mais sentido a algumas das atividades que desenvolviam como os trabalhos e estudos nos Núcleos de Base e a relação com suas 


\section{Revista do Programa de Pós-Graduação em Educação da Unochapecó ISSN 1984-1566 (on-line) ISSN 1415-8175 (impressa)}

famílias e comunidades. Ganharam ainda maiores possibilidades de se expressar nos trabalhos das disciplinas e no conjunto da escola, além de se associarem com outros estudantes ou aspectos da vida. Porém, estas conquistas são limitadas pela deterioração do futuro dos jovens, visível nas políticas neoliberais e neofascistas que se fazem sentir nos jovens das escolas; estão mais desmotivados, mais sujeitos à violência e drogas e, portanto, mais vulneráveis a se afastarem dos estudos.

Tomamos o trabalho que se realiza nestas escolas como uma aproximação aos complexos de estudo da Pedagogia Soviética. A proposta não pode ser efetivada em toda sua profundidade e potencial nas atuais condições de formação e trabalho docente. Alguns limites que se fazem sentir são, dentre outros, a fragmentação do tempo e dos espaços escolares e a pequena margem de manobra das escolas quanto a estes aspectos; docentes com domínio insuficiente de conteúdo nas disciplinas em que atuam o que leva à relações superficiais entre o conhecimento e o real; a articulação entre as disciplinas, a autoorganização dos estudantes e o TSN ainda pontual, episódica; condições de vida e trabalho docente e discente que dificultam sobremaneira o estudo sistemático, a construção do pensamento teórico e o trabalho coletivo, aspectos estes essenciais para a construção de outra escola e de outra sociedade.

A experiência das escolas retratadas neste artigo fortalece em nós algumas convicções: os professores precisam de tempo e condições para estudar, individual e coletivamente. Estudar a escola, os grandes temas da atualidade e suas próprias disciplinas. Apenas um conhecimento aprofundado do conteúdo a ser ensinado é capaz de revelar melhor suas conexões com a vida e a interdependência do conhecimento. A formação aligeirada de professores e as condições precárias do trabalho docente limitam ou mesmo impedem a realização mais plena da proposta. Porém, o esforço de seu coletivo revela algumas possibilidades, se não de demover estas barreiras, sermos mais conscientes delas. As formas de organização coletiva nos assentamentos e seus vínculos com o Movimento Social são não apenas a base que criou as escolas e as impulsionou, mas adentram o seu trabalho pedagógico tendo por objetivo que a educação, os sujeitos e a sociedade se libertem de todas as formas de exploração e opressão.

As condições para fazer uma nova escola não estão prontas. A proposta dos complexos de estudo da Pedagogia Socialista esbarra nestes limites, encontrando 
dificuldade em se realizar de forma mais plena. Ao mesmo tempo, contudo, são estas mesmas condições que empurram em direção à outra proposta de escola e de pedagogia, pois professores e estudantes revelam no seu cotidiano a necessidade e ansiedade por novas relações sociais e educativas que nos formem como sujeitos plenos de possibilidades.

\section{REFERÊNCIAS}

BICALHO, Ramofly. A dimensão educativa e o fazer pedagógico no Movimento dos Trabalhadores Rurais Sem Terra. Revista Pedagógica, v. 23, p. 1-21, 2021.

DALMAGRO, Sandra Luciana; MOURA, Ezequiel Augusto. A experiência pedagógica com os complexos de estudo no Curso de Ensino Médio/EJA/PRONERA/UFSC. Anais do I Seminário Internacional e I Fórum de Educação do Campo da Região Sul do RS. Pelotas: Ed. Da UFPEL, 2012. CD-ROM.

DALMAGRO, Sandra Luciana. Forma Escolar e complexos de estudos: considerações a partir das escolas itinerantes do MST. Germinal: Marxismo e Educação em Debate, Salvador, v. 8, n. 2, p. 100-109, dez. 2016.

ENGUITA, Mariano Fernández. A face oculta da escola: educação e trabalho no capitalismo. Porto Alegre: Artes Médicas, 1989.

ESCOLA PAULO FREIRE. Projeto Político e Pedagógico. Abelardo Luz, 2018.

ESCOLAS, Paulo Freire e Semente da Conquista. Objetivos Formativos. Abelardo Luz, 2015.

FERNANDES, Bernardo Mançano. Movimentos socioterritoriais e movimentos socioespaciais. Revista NERA, n. 6, 2005.

FERNANDES, Bernardo Mançano. Sobre a tipologia de territórios. In: SAQUET, Marcos Aurélio; SPOSITO, Eliseu Savério (Orgs.). Territórios e Territorialidades. São Paulo: Expressão Popular, 2009.

FREIRE, Paulo. Pedagogia da autonomia. São Paulo: Paz e Terra, 2002.

FREITAS, Luiz Carlos de. A luta por uma pedagogia do meio: revisitando o conceito. In: PISTRAK, Moisey Mikhaylovich (org.). A Escola-Comuna. São Paulo: Expressão Popular, 2009. 


\section{REVISTA}

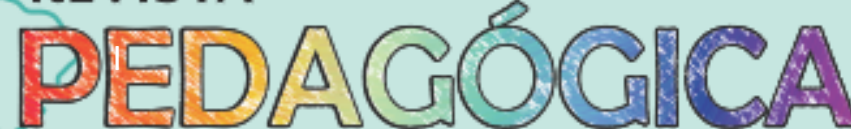

Revista do Programa de Pós-Graduação em Educação da Unochapecó

ISSN 1984-1566 (on-line) ISSN 1415-8175 (impressa)

KRUPSKAYA, N. K. A construção da Pedagogia Socialista. São Paulo: Expressão Popular, 2017.

MST PR (org). Plano de Estudos: Escolas Itinerantes do Estado do Paraná. Cascavel, 2013.

NARKOMPROS. A Educação na República dos Soviets: programas oficiais, SP: Editora Nacional, 1935.

PISTRAK, Moisey Mikhaylovich. Fundamentos da Escola do Trabalho. São Paulo: Expressão Popular, 2000.

PISTRAK, Moisey Mikhaylovich. (org.). A Escola-Comuna. São Paulo: Expressão Popular, 2009.

PISTRAK, Moisey Mikhaylovich. Ensaios sobre a escola politécnica. São Paulo: Expressão Popular, 2015.

PISTRAK, Moisey Mikhaylovich. Fundamentos da Escola do Trabalho. São Paulo: Expressão Popular, 2018.

SHULGIN, Viktor Nikholaevich. Rumo ao Politecnismo, 1. Ed. São Paulo: Expressão Popular, 2013. 